Article

\title{
Synbiotic Combination of Djulis (Chenopodium formosanum) and Lactobacillus acidophilus Inhibits Colon Carcinogenesis in Rats
}

\author{
Chih-Wei Lee ${ }^{1}$, Hong-Jhang Chen ${ }^{2}$, Yu-Hua Chien ${ }^{1}$, Shih-Min Hsia ${ }^{1,3,4,5}{ }^{\mathbb{D}}$, Jiann-Hwa Chen ${ }^{6}$ \\ and Chun-Kuang Shih 1,4,7,*(D) \\ 1 School of Nutrition and Health Sciences, College of Nutrition, Taipei Medical University, Taipei 11031, \\ Taiwan; leechihwei1012@gmail.com (C.-W.L.); betty3482@gmail.com (Y.-H.C.); \\ bryanhsia@tmu.edu.tw (S.-M.H.) \\ 2 Institute of Food Science and Technology, National Taiwan University, Taipei 10617, Taiwan; \\ fsthjchen@ntu.edu.tw \\ 3 Graduate Institute of Metabolism and Obesity Sciences, College of Nutrition, Taipei Medical University, \\ Taipei 11031, Taiwan \\ 4 School of Food Safety, College of Nutrition, Taipei Medical University, Taipei 11031, Taiwan \\ 5 Nutrition Research Center, Taipei Medical University Hospital, Taipei 11031, Taiwan \\ 6 Division of Gastroenterology and Hepatology, Department of Internal Medicine, Taipei Tzu Chi Hospital, \\ New Taipei City 23142, Taiwan; cjhki.tiyi@msa.hinet.net \\ 7 Master Program in Food Safety, College of Nutrition, Taipei Medical University, Taipei 11031, Taiwan \\ * Correspondence: ckshih@tmu.edu.tw; Tel.: +886-(2)-2736-1661 (ext. 6569)
}

Received: 24 November 2019; Accepted: 26 December 2019; Published: 30 December 2019

check for updates

\begin{abstract}
Djulis is a functional grain containing prebiotic dietary fiber, which has an anti-cancer potential. This study examined the preventive effect of djulis alone or in combination with Lactobacillus acidophilus on colon carcinogenesis induced by 1,2-dimethylhydrazine (DMH) and dextran sulfate sodium (DSS). Rats were divided into five groups and fed B (AIN-93G, blank), C (AIN-93G, control), D (10\% djulis), DLA (10\% djulis plus $5 \times 10^{6} \mathrm{cfu} \mathrm{L.} \mathrm{acidophilus/g),} \mathrm{and} \mathrm{DHA}$ (10\% djulis plus $5 \times 10^{7} \mathrm{cfu}$ L. acidophilus/g) diets, respectively. All rats except for those in group B received three doses of DMH (40 mg/kg) by intraperitoneal injection and 3\% DSS in drinking water. After 10 weeks of feeding, the colon was analyzed for precancerous lesions and biomarkers. DMH and DSS treatment induced aberrant crypt foci (ACF), especially in the distal colon. D, DLA, and DHA significantly reduced the numbers of total ACF, sialomucin-producing ACF (SIM-ACF), and mucin-depleted foci (MDF) in the distal colon compared to C. Additionally, DLA and DHA further downregulated the expressions of proliferating cell nuclear antigen (PCNA) and cyclooxygenase-2 (COX-2) and regulated apoptosis-related proteins. These results suggest that synbiotic combination of djulis and L. acidophilus shows the best inhibitory effect on colon carcinogenesis via regulation of proliferative, inflammatory, and apoptotic pathways.
\end{abstract}

Keywords: djulis; Lactobacillus acidophilus; synbiotics; colon cancer; apoptosis

\section{Introduction}

Colorectal cancer (CRC) is the third most commonly diagnosed cancer worldwide [1]. Diet and lifestyle are closely associated with CRC. Previous studies pointed out that dietary pattern could significantly affect the risk of cancer [2]. Western diet, a diet high in fat and low in dietary fiber, increase the risk of CRC [3]. 
The development of CRC is a multiple and long-term process, including initiation, promotion, progression, and invasion. Inflammation and oxidative stress may initiate and promote CRC development. Cyclooxygenase-2 (COX-2) mediates inflammation and plays an important role in CRC. Increased COX-2 expression has been detected in both colorectal tumor-bearing animals [4] and CRC patients [5].

Overexpression of COX-2 can inhibit apoptosis, including both intrinsic and extrinsic pathways [6]. In CRC cells, reduction of B-cell lymphoma 2 (Bcl-2) protein expression and enhancement of Bcl-2-associated $X$ (Bax) protein expression significantly inhibited cancer cell proliferation [7]. In addition, upregulation of caspase- 3 , caspase- 8 , and caspase- 9 could promote apoptosis in HCT-116 cells [8]. These studies suggest that the increased expression of pro-apoptotic proteins and the decreased expression of anti-apoptotic proteins play a key role in the control of CRC.

Aberrant crypt foci (ACF), a precancerous lesion in the colon, have been generally accepted for use as a biomarker to investigate the effects of dietary factors on colon carcinogenesis in rats since it was first reported by Bird in 1987 [9]. Intestinal goblet cells secrete two different mucins, the sulfomucin (SUM) and the sialomucin (SIM) [10]. According to different mucin production, ACF can be classified into sulfomucin-producing ACF (SUM-ACF), sialomucin-producing ACF (SIM-ACF), and mucin-depleted foci (MDF). MDF with absent or scant secretion of mucin are positively correlated to the number of colonic tumors [11]. MDF become larger over time and spread more in the distal colon, thus they are an indicator of precancerous lesions and can be used as a short-term endpoint for CRC studies [12]. Therefore, ACF and their produced mucins can be used as good biomarkers to detect the efficacy of chemopreventive agents in colon carcinogenesis.

Djulis (Chenopodium formosanum) is a native cereal crop planted in Taiwan and traditionally called "ruby of cereals" for its bright red color. Djulis has many health benefits, such as anti-adipogenesis [13] and recovering liver injury [14,15]. Some studies found that the color of djulis was mainly from betalains, including betanin, isobetanin, amaranthine, and isoamaranthine, which were directly related to its antioxidant capacity [16]. Moreover, djulis contains high levels of dietary fiber, proteins, and grain-limited essential amino acids (e.g., lysine) [17].

Certain dietary fiber, as a good prebiotics, can promote the growth of the intestinal bacterial population towards a relative increase in Bifidobacterium and/or Lactobacillus species [18]. Some studies have indicated that modulation of the gut microbiota positively affects the interaction between microbiota and the host immune system, and thus may be beneficial in suppressing CRC development [19]. Moreover, emerging studies suggest that synbiotics, the combination of prebiotics and probiotics, are more effective in preventing CRC than either prebiotics or probiotics alone [20].

Our previous study demonstrated that dietary djulis inhibited the development of precancerous lesions of CRC in a carcinogen-induced animal model [21]. Besides, we also found that Lactobacillus acidophilus reduced inflammation in lipopolysaccharide (LPS)- and tumor necrosis factor alpha (TNF- $\alpha)$-induced inflammatory colon cancer cells [22]. However, the effect of combination of djulis and probiotics and the detailed mechanism of action remain to be elucidated. The aim of this study was to investigate the preventive effect of djulis combined with L. acidophilus on colon carcinogenesis in a rat model.

\section{Materials and Methods}

\subsection{Materials}

Djulis was acquired from Sinfong Agritech Co. (Taipei, Taiwan). L. acidophilus LA-5 ${ }^{\circledR}$ powder was from Chr. Hansen (Hørsholm, Denmark). BD Difco ${ }^{\text {TM }}$ Lactobacilli MRS Broth was purchased from BD ${ }^{\mathrm{TM}}$ (Franklin Lakes, NJ, USA). Methylene blue, acetic acid, and iron (III) chloride hexahydrate were purchased from Nacalai Tesque Inc. (Tokyo, Japan), Showa Chemicals Co. (Tokyo, Japan) and Shimakyu Pure Chemicals (Osaka, Japan), respectively. Caspase-3 antibody (GTX110543) was purchased from Genetex Inc. (Irvine, CA, USA). Bax antibody (Catalogue number: 2772) and Bcl-2 
antibody (Catalogue number: 2870) were purchased from Cell Signaling Technology Inc. (Danvers, MA, USA). Proliferating cell nuclear antigen (PCNA) antibody (Catalogue number: 13110), Goat anti-rabbit IgG secondary antibody, peroxidase AffiniPure goat anti-mouse IgG, and COX-2 antibody (Catalogue number: ab6665) were purchased from Abcam (Cambridge, UK), Southern Biotechnology Associates, Inc. (Birmingham, AL, USA) and Jackson ImmunoResearch Inc. (West Grove, PA, USA), respectively. Antibody dilutions for caspase-3, Bax, Bcl-2, PNCA, and COX-2 were 1: 2000, 1:1000, 1:1000, 1:1000, and 1:5000, respectively. $\beta$-Actin antibody, 1,2-dimethylhydrazine (DMH), dextran sulfate sodium (DSS) salt from Leuconostoc, N, $N^{\prime}$-dimethyl-m-phenylenediamine, Alcian blue, $\mathrm{N}$, $N^{\prime}$-dimethyl-p-phenylenediamine, agar, and the other chemicals were all purchased from Sigma Chemical Co. (St. Louis, MO, USA).

\subsection{Experimental Diets}

The experimental diet was an AIN-93G-based diet containing djulis alone or in combination with L. acidophilus. The content of L. acidophilus LA- $5^{\circledR}$ in powder was $6 \times 10^{10}$ colony-forming unit (cfu)/g. Diets were stored at room temperature and then analyzed for the bacteria count [23] to ensure that the doses of groups DLA and DHA were $5 \times 10^{6} \mathrm{cfu}$ L. acidophilus LA- $5^{\circledR} / \mathrm{g}$ and $5 \times 10^{7} \mathrm{cfu}$ L. acidophilus LA- $5^{\circledR} / \mathrm{g}$, respectively (Figure 1 ).

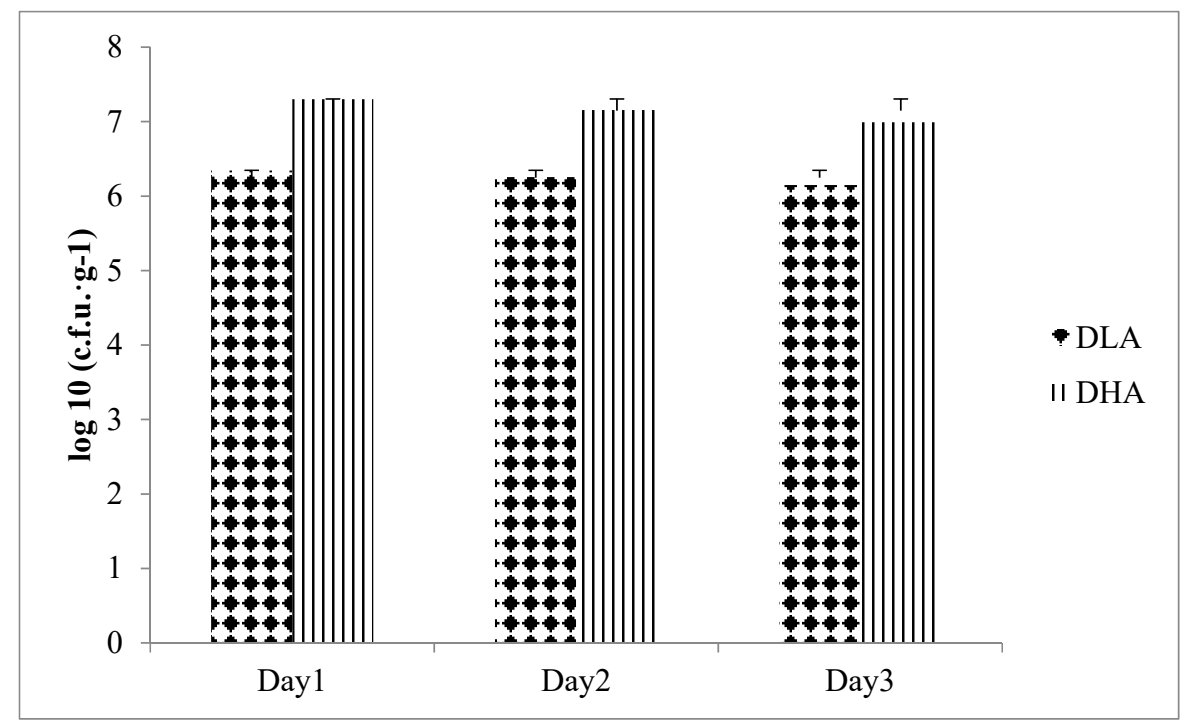

Figure 1. Total plate count of Lactobacillus acidophilus in diets. DLA, AIN-93G containing $10 \%$ djulis + $5 \times 10^{6} \mathrm{cfu}$ L. acidophilus/g; DHA, AIN-93G containing 10\% djulis $+5 \times 10^{7} \mathrm{cfu}$ L. acidophilus/g.

\subsection{Animals and Treatments}

The protocol used herein was approved by the Institutional Animal Care and Use Committee (IACUC) of Taipei Medical University. The approval number is LAC-2015-0400. Sixty male F344 rats (3-5 weeks old) were from National Laboratory Animal Center (Taipei, Taiwan) and housed under standard conditions $\left(21 \pm 2{ }^{\circ} \mathrm{C}, 40-60 \%\right.$ humidity under a 12-h light-dark cycle). The rats had free access to diet and water. After an adaptation period (1 week), the rats were randomized into 5 groups (12 rats per group) and fed B (AIN-93G, blank), C (AIN-93G, control), D (10\% djulis), DLA (10\% djulis plus $5 \times 10^{6} \mathrm{cfu} / \mathrm{g}$ of L. acidophilus LA- $\left.5^{\circledR}\right)$, and DHA (10\% djulis plus $5 \times 10^{7} \mathrm{cfu} / \mathrm{g}$ of L. acidophilus LA- $5^{\circledR}$ ) diets, respectively (Table 1 ). The composition of djulis and experimental diet are shown in Tables 2 and 3, respectively. After one week of experimental diet feeding, rats in groups C, D, DLA, and DHA were given intraperitoneal injections of DMH $(40 \mathrm{mg} / \mathrm{kg})$ for 3 consecutive days during the second week of dietary treatment, and after DMH injection, these groups were treated with $3 \%$ DSS in drinking water for one week (Figure 2). The fresh experimental diets were supplied every three days. 
Body weight and feed consumption were measured every three days during the experimental period. After 10 weeks of feeding, all rats were sacrificed and the cecum, colons, and feces were collected and examined for precancerous lesions and biomarkers.

Table 1. Experimental groups.

\begin{tabular}{ccc}
\hline Group & Treatment & Diet \\
\hline Blank (B) & Saline/Sterile water & AIN-93G \\
\hline Control (C) & DMH/DSS & AIN-93G \\
\hline Djulis (D) & DMH/DSS & AIN-93G containing 10\% djulis \\
\hline Djulis + low dose of L. acidophilus (DLA) & DMH/DSS & $\begin{array}{c}\text { AIN-93G containing 10\% djulis } \\
+5 \times 10^{6} \text { cfu/g of L. acidophilus LA-5 } 5^{\circledR}\end{array}$ \\
\hline Djulis + high dose of L. acidophilus (DHA) & DMH/DSS & $\begin{array}{c}\text { AIN-93G containing 10\% djulis } \\
+5 \times 10^{7} \text { cfu/g of L. acidophilus LA-5 } 5^{\circledR}\end{array}$ \\
\hline
\end{tabular}

Table 2. The composition of djulis.

\begin{tabular}{cc}
\hline Composition & Content $\mathbf{( g / 1 0 0 ~ g ) ~}$ \\
\hline Moisture & 10.34 \\
Ash & 6.98 \\
Crude fat & 6.43 \\
Crude protein & 11.94 \\
Total dietary fiber $^{1}$ & 18.54 \\
Nitrogen-free extract $^{1}$ & 45.77 \\
\hline
\end{tabular}

\footnotetext{
${ }^{1}$ Nitrogen-free extract: $100-$ moistu-a-crude $\mathrm{f}-$ crude prote-total dietary fiber.
}

Table 3. The composition of the experimental diet.

\begin{tabular}{cccccc}
\hline Composition & \multicolumn{5}{c}{ Content (g/kg Diet) } \\
\cline { 2 - 6 } & B & C & D & DLA & DHA \\
\hline Djulis & - & - & 100 & 100 & 100 \\
L. acidophilus powder & - & - & - & 0.083 & 0.83 \\
Cornstarch & 397.5 & 397.5 & 334.41 & 334.41 & 334.41 \\
Casein & 200 & 200 & 188.06 & 188.06 & 188.06 \\
Dextrinized cornstarch & 132 & 132 & 132 & 132 & 132 \\
Sucrose & 100 & 100 & 100 & 100 & 100 \\
Soybean oil & 70 & 70 & 63.57 & 63.57 & 63.57 \\
$\alpha$-Cellulose & 50 & 50 & 31.46 & 31.46 & 31.46 \\
Mineral mix & 35 & 35 & 35 & 35 & 35 \\
Vitamin mix & 10 & 10 & 10 & 10 & 10 \\
L-cystine & 3 & 3 & 3 & 3 & 3 \\
Choline bitartrate & 2.5 & 2.5 & 2.5 & 2.5 & 2.5 \\
tert-Butylhydroquinone $(\mathrm{mg})$ & 14 & 14 & 14 & 14 & 14 \\
\hline
\end{tabular}

DMH or saline injection (i.p.) on day 1, 2, 3 of week 1

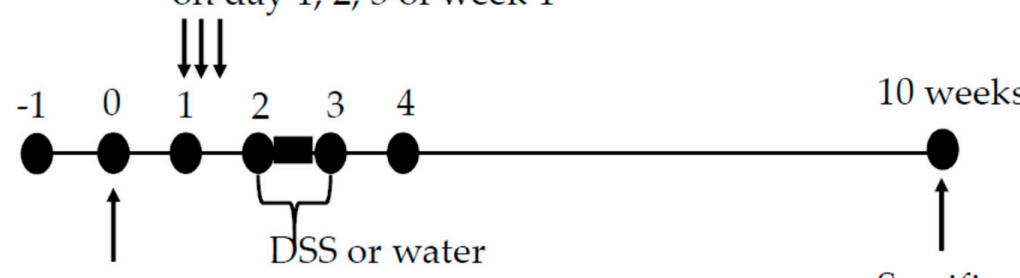

Experimental diet

Sacrificed

Figure 2. The experimental process. 


\subsection{Fecal L. acidophilus Counting}

Serial dilutions of feces were conducted on Lactobacilli MRS Broth-agar. The count of fecal L. acidophilus was determined on the above-mentioned medium [24].

\subsection{Measurement of the Cecum}

The cecum was excised, weighed, and then split open [25]. The weights of the cecum wall and content were also recorded.

\subsection{Analysis of Colonic ACF}

ACF were analyzed by the method described in our previous study [26]. The colon was removed, opened longitudinally and rinsed in saline, and then fixed flat between filter papers in $10 \%$ buffered formalin for $24 \mathrm{~h}$. After being stained with $0.2 \%$ methylene blue solution for $5 \mathrm{~min}$, fixed sections were placed on microscopic slides and the mucosal side was examined under a light microscope (Nikon Corp., Tokyo, Japan) at 40× magnification. Total numbers of ACF and aberrant crypts (ACs) in each focus were counted and the colonic area was calculated by NIS-Elements microscope imaging software (Nikon Corp., Tokyo, Japan). All data of ACF and AC were presented as number $/ \mathrm{cm}^{2}$.

\subsection{Determination of Mucin Production in ACF}

The distal colons were immersed in $75 \%$ ethanol for fading after being stained with methylene blue, and then stained with high-iron diamine Alcian blue (HIDAB). The colons were observed under a light microscope (Nikon Corp., Tokyo, Japan) at 40× magnification. ACF stained bright or dark blue indicated SIM production while those stained dark brown indicated SUM production. The definition of SUM-ACF were samples with more than 85\% SUM-producing cells, and for SIM-ACF were those with more than $85 \%$ SIM-producing cells. Those with not more than $85 \%$ SUM-producing or $85 \%$ SIM-producing cells were defined as mixed-type (MIX)-ACF. Furthermore, foci with very little or no secretion of any mucin were defined as MDF [27]. The colonic area was calculated by NIS-Elements microscope imaging software (Nikon Corp., Tokyo, Japan). Data of SIM-, SUM-, MIX-ACF, and MDF were presented as number $/ \mathrm{cm}^{2}$.

\subsection{Analysis of Protein Expression}

Colon samples were homogenized in in five volumes of modified radioimmunoprecipitation assay (RIPA) buffer (0.5 M Tris- $\mathrm{HCl}, 2.5 \%$ deoxycholic acid, $1.5 \mathrm{M} \mathrm{NaCl}, 10 \% \mathrm{NP}-40,10 \mathrm{mM}$ ethylenediaminetetraacetic acid, $\mathrm{pH}$ 7.4) and 10\% protease inhibitor cocktail. The supernatants of homogenates were collected by centrifuging the homogenates at $10,000 \times g$ at $4{ }^{\circ} \mathrm{C}$ for $15 \mathrm{~min}$. The total protein concentration of supernatants was confirmed by Bradford protein assay. Western blot was used for protein analysis. Protein samples were separated on $10 \%$ sodium dodecyl sulfate polyacrylamide gels (SDS-PAGE) and transferred to polyvinylidene difluoride membranes. After blocking with 5\% bovine serum albumin (BSA) in Tris-buffered saline containing $1 \%$ Tween 20 (TBST), the membranes were incubated with the appropriate antibodies at $4{ }^{\circ} \mathrm{C}$ for $16 \mathrm{~h}$. The membranes were then washed with TBST and incubated with anti-mouse or anti-rabbit horseradish peroxidase-conjugated secondary antibodies for $1 \mathrm{~h}$. After washing with TBST, the immunocomplexes were visualized by chemiluminescence reagents and detected by chemiluminometer (BioSpectrum AC Imaging System, Ultra-Violet Products Ltd., Cambridge, United Kingdom).

\subsection{Statistical Analysis}

Data were presented as means \pm SD. Differences among the experimental data were assessed by one-way analysis of variance (ANOVA) followed by Duncan's multiple range test. All statistical analyses were carried out using the SAS software (SAS Institute, Cary, NC, USA). All $p$ values $<0.05$ were considered statistically significant. 


\section{Results}

\subsection{Animal Growth and Fecal L. acidophilus Count}

There were no differences in body weight gain, feed consumption, and feed efficiency among groups (data not shown). Group C demonstrated a slight but insignificant decrease in fecal L. acidophilus count compared to group B (Figure 3). Group DHA had a significantly higher fecal L. acidophilus count than group $C$ while the counts of fecal L. acidophilus were similar among groups C, D, and DLA (Figure 3).

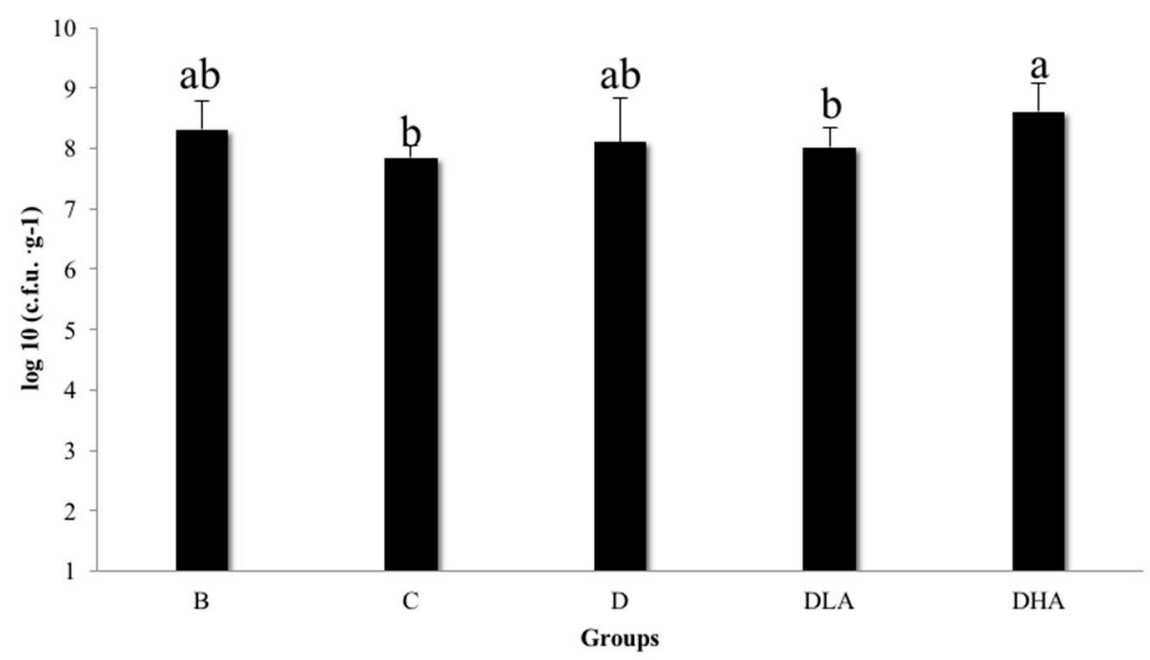

Figure 3. Total count of fecal Lactobacillus acidophilus in F344 rats. All rats except those in group B were administered with DMH/DSS. B, AIN-93G diet; C, AIN-93G diet; D, AIN-93G containing 10\% djulis; DLA, AIN-93G containing 10\% djulis $+5 \times 10^{6} \mathrm{cfu}$ L. acidophilus/g; and DHA, AIN-93G containing 10\% djulis $+5 \times 10^{7} \mathrm{cfu}$ L. acidophilus/g. Different letters above the error bars indicate a significant difference as determined by one-way ANOVA followed by Duncan's multiple-range test, $p<0.05(n=12)$.

\subsection{Cecum Weight and $p H$ Value}

There were no differences in the cecum wall weight and relative cecum wall weight among groups (Table 4). Groups D, DLA, and DHA had a significantly higher cecum weight, relative cecum weight, cecum content weight, and relative cecum content weight than group $C$ (Table 4). There was no difference in cecal $\mathrm{pH}$ value between groups $\mathrm{B}$ and $\mathrm{C}$; however, significantly lower cecal $\mathrm{pH}$ values were observed in groups D, DLA, and DHA compared to group C (Supplementary Figure S1).

Table 4. Effects of djulis and Lactobacillus acidophilus on the weights of the cecum, cecum wall, and cecum content of male F344 rats ${ }^{1,2}$.

\begin{tabular}{ccccccc}
\hline Group $^{3}$ & $\begin{array}{c}\text { Cecum } \\
\text { Weight (g) }\end{array}$ & $\begin{array}{c}\text { Relative } \\
\text { Cecum } \\
\text { Weight } \\
(\mathbf{g} / \mathbf{1 0 0} \mathbf{g ~ B W})\end{array}$ & $\begin{array}{c}\text { Cecum Wall } \\
\text { Weight (g) }\end{array}$ & $\begin{array}{c}\text { Relative } \\
\text { Cecum Wall } \\
\text { Weight } \\
(\mathbf{g} / \mathbf{1 0 0} \mathbf{~ g ~ B W})\end{array}$ & $\begin{array}{c}\text { Cecum } \\
\text { Content } \\
\text { Weight (g) }\end{array}$ & $\begin{array}{c}\text { Relative Cecum } \\
\text { Content Weight } \\
(\mathbf{g} / \mathbf{1 0 0} \mathbf{g ~ B W})\end{array}$ \\
\hline $\mathrm{B}$ & $1.6 \pm 0.7^{\mathrm{b}}$ & $0.4 \pm 0.2^{\mathrm{b}}$ & $0.5 \pm 0.2^{\mathrm{a}}$ & $0.14 \pm 0.05^{\mathrm{a}}$ & $1.1 \pm 0.6^{\mathrm{b}}$ & $0.3 \pm 0.2^{\mathrm{b}}$ \\
$\mathrm{C}$ & $1.8 \pm 0.4^{\mathrm{b}}$ & $0.5 \pm 0.1^{\mathrm{b}}$ & $0.6 \pm 0.1^{\mathrm{a}}$ & $0.15 \pm 0.02^{\mathrm{a}}$ & $1.2 \pm 0.4^{\mathrm{b}}$ & $0.3 \pm 0.1^{\mathrm{b}}$ \\
$\mathrm{D}$ & $2.3^{\mathrm{a}} \pm 0.7^{\mathrm{a}}$ & $0.6 \pm 0.2^{\mathrm{a}}$ & $0.6 \pm 0.1^{\mathrm{a}}$ & $0.15 \pm 0.02^{\mathrm{a}}$ & $1.7 \pm 0.7^{\mathrm{a}}$ & $0.5 \pm 0.2^{\mathrm{a}}$ \\
DLA & $2.5 \pm 0.6^{\mathrm{a}}$ & $0.7 \pm 0.1^{\mathrm{a}}$ & $0.6 \pm 0.0^{\mathrm{a}}$ & $0.16 \pm 0.01^{\mathrm{a}}$ & $1.9 \pm 0.6^{\mathrm{a}}$ & $0.5 \pm 0.1^{\mathrm{a}}$ \\
DHA & $2.4 \pm 0.5^{\mathrm{a}}$ & $0.7 \pm 0.1^{\mathrm{a}}$ & $0.6 \pm 0.1^{\mathrm{a}}$ & $0.16 \pm 0.02^{\mathrm{a}}$ & $1.8 \pm 0.5^{\mathrm{a}}$ & $0.5 \pm 0.1^{\mathrm{a}}$ \\
\hline
\end{tabular}

${ }^{1}$ All values are mean $\pm \mathrm{SD}(n=12) .{ }^{2}$ Values with the different superscript letters in a column are significantly different from one another as determined by one-way ANOVA followed by Duncan's multiple range test, $p<0.05$. ${ }^{3}$ All rats except those in group B were administered with DMH/DSS. B, AIN-93G diet; C, AIN-93G diet; D, AIN-93G containing $10 \%$ djulis; DLA, AIN-93G containing $10 \%$ djulis $+5 \times 10^{6} \mathrm{cfu}$ L. acidophilus/g; DHA, AIN-93G containing $10 \%$ djulis $+5 \times 10^{7} \mathrm{cfu}$ L. acidophilus/g. 


\subsection{ACF in the Colon}

All DMH/DSS-treated groups successfully induced ACF formation as the incidences of ACF shown in groups C, D, DLA, and DHA were all 100\%. The representative images of ACF and MDF in this study are shown in Figure 4. Group DHA had a significantly lower total ACF number in the colon than group C (Table 5). According to previous studies, ACF could be distinguished into small (one to three crypts per focus) and large (four or more crypts per focus) ones [28]. Groups DLA and DHA had a significantly lower number of large ACF than group C (Table 5). ACF were mainly observed in the distal colon. Groups D, DLA, and DHA had a significantly lower number of distal ACF compared to group C (Table 6). We further examined the various sizes of ACF present in the distal colon and the results showed that groups D, DLA, and DHA had significantly lower numbers of small ACF compared to group C (Table 7). Groups D and DHA significantly inhibited the formation of large ACF in the distal colon while there was no distal large ACF in group DLA (Table 7).
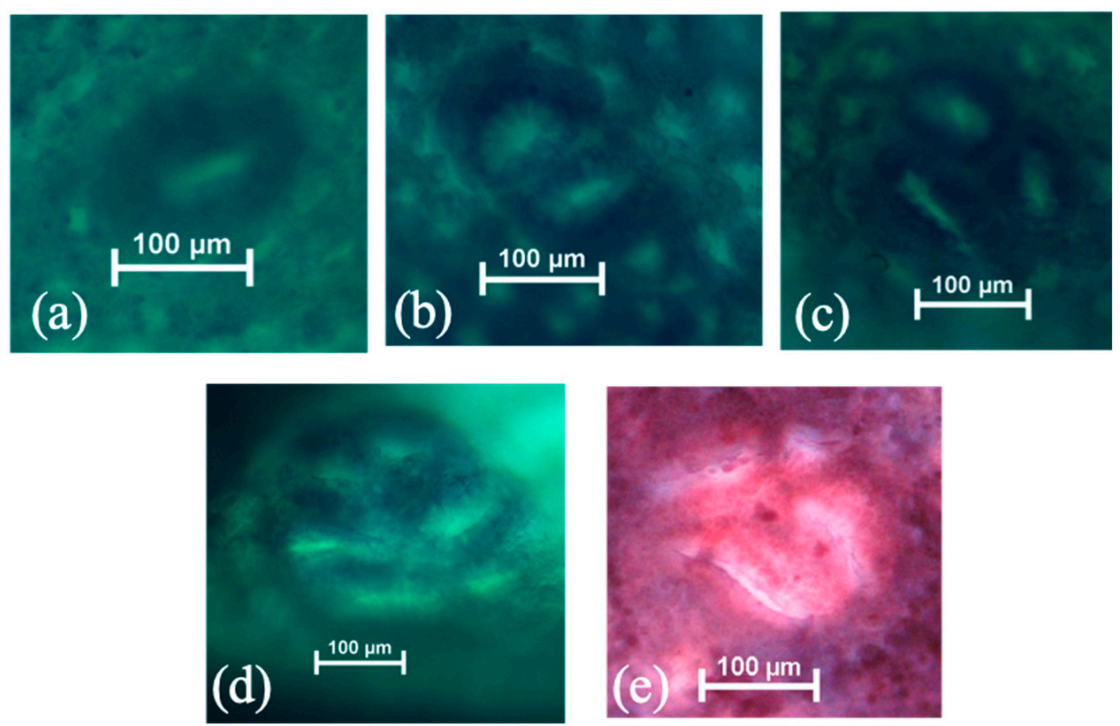

Figure 4. The representative images of aberrant crypt foci (ACF) with one (a), two (b), three (c), and six (d) crypts, as well as mucin-depleted foci (MDF, (e)) in DMH/DSS-induced male F344 rats. The original magnification is $100 \times$.

Table 5. Effects of djulis and Lactobacillus acidophilus on DMH/DSS-induced ACF in the colon of male F344 rats ${ }^{1,2}$.

\begin{tabular}{ccccc}
\hline Group $^{3}$ & $\begin{array}{c}\text { ACF Incidence (\% of } \\
\text { Animals with ACF) }\end{array}$ & $\begin{array}{c}\text { Number of ACF } \\
\left(\mathbf{N u m b e r} / \mathbf{c m}^{\mathbf{2}}\right)\end{array}$ & $\begin{array}{c}\text { Small ACF } \\
(\leq 3 \text { Crypts) }\end{array}$ & $\begin{array}{c}\text { Large ACF } \\
(\geq 4 \text { Crypts) }\end{array}$ \\
\hline C & $100 \%$ & $6.5 \pm 2.4^{\mathrm{a}}$ & $6.1 \pm 2.0^{\mathrm{a}}$ & $0.4 \pm 0.4^{\mathrm{a}}$ \\
D & $100 \%$ & $5.9 \pm 1.9^{\mathrm{ab}}$ & $5.6 \pm 1.9^{\mathrm{a}}$ & $0.3 \pm 0.2^{\mathrm{ab}}$ \\
DLA & $100 \%$ & $5.5 \pm 1.9^{\mathrm{ab}}$ & $5.4 \pm 1.8^{\mathrm{a}}$ & $0.1 \pm 0.1^{\mathrm{b}}$ \\
DHA & $100 \%$ & $5.1 \pm 1.6^{\mathrm{b}}$ & $4.9 \pm 1.5^{\mathrm{a}}$ & $0.1 \pm 0.2^{\mathrm{b}}$ \\
\hline
\end{tabular}

${ }^{1}$ Values are percentage or mean $\pm \mathrm{SD}(n=12) .{ }^{2}$ Values with the different superscript letters in a column are significantly different from one another as determined by one-way ANOVA followed by Duncan's multiple range test, $p<0.05 .{ }^{3}$ All rats were administered with DMH/DSS. C, AIN-93G diet; D, AIN-93G containing 10\% djulis; DLA, AIN-93G containing $10 \%$ djulis $+5 \times 10^{6} \mathrm{cfu}$ L. acidophilus/g; DHA, AIN-93G containing $10 \%$ djulis $+5 \times 10^{7} \mathrm{cfu}$ L. acidophilus/g. 
Table 6. Effects of djulis and Lactobacillus acidophilus on the distribution of DMH/DSS-induced ACF in the colon of male F344 rats ${ }^{1,2}$.

\begin{tabular}{cccc}
\hline Group $^{3}$ & Proximal Colon & Middle Colon & Distal Colon \\
\hline C & $3.2 \pm 1.3^{\mathrm{a}}$ & $7.4 \pm 2.6^{\mathrm{a}}$ & $11.8 \pm 5.3^{\mathrm{a}}$ \\
D & $2.2 \pm 2.2^{\mathrm{a}}$ & $7.0 \pm 1.8^{\mathrm{a}}$ & $8.0 \pm 3.4^{\mathrm{b}}$ \\
DLA & $2.5 \pm 2.8^{\mathrm{a}}$ & $6.5 \pm 3.0^{\mathrm{a}}$ & $7.6 \pm 2.0^{\mathrm{b}}$ \\
DHA & $2.6 \pm 2.7^{\mathrm{a}}$ & $6.4 \pm 3.3^{\mathrm{a}}$ & $6.3 \pm 2.7^{\mathrm{b}}$ \\
\hline
\end{tabular}

${ }^{1}$ All values are mean $\pm \mathrm{SD}(n=12) .{ }^{2}$ Values with the different superscript letters in a column are significantly different from one another as determined by one-way ANOVA followed by Duncan's multiple range test, $p<0.05$. ${ }^{3}$ All rats were administered with DMH/DSS. C, AIN-93G diet; D, AIN-93G containing 10\% djulis; DLA, AIN-93G containing $10 \%$ djulis $+5 \times 10^{6} \mathrm{cfu}$ L. acidophilus/g; DHA, AIN-93G containing $10 \%$ djulis $+5 \times 10^{7} \mathrm{cfu}$ L. acidophilus/g.

Table 7. Effects of djulis and Lactobacillus acidophilus on ACF (number/ $\mathrm{cm}^{2}$ ) according to the various sizes of crypts in the distal colon of male F344 rats ${ }^{1,2}$.

\begin{tabular}{|c|c|c|c|c|c|}
\hline \multirow{2}{*}{ Group $^{4}$} & \multicolumn{3}{|c|}{ ACF with } & \multirow{2}{*}{$\begin{array}{l}\text { Small ACF } \\
\text { ( } \leq 3 \text { Crypts) }\end{array}$} & \multirow{2}{*}{$\begin{array}{l}\text { Large ACF } \\
\text { ( } \geq 4 \text { Crypts }\end{array}$} \\
\hline & 1 Crypt & 2 Crypts & 3 Crypts & & \\
\hline $\mathrm{C}$ & $6.6 \pm 2.3^{a}$ & $3.0 \pm 2.3^{a}$ & $1.1 \pm 1.3^{a}$ & $10.6 \pm 4.3^{a}$ & $1.2 \pm 1.1^{\mathrm{a}}$ \\
\hline $\mathrm{D}$ & $3.7 \pm 2.4^{b}$ & $2.4 \pm 1.3^{\mathrm{a}}$ & $1.2 \pm 0.8^{a}$ & $7.4 \pm 3.2^{b}$ & $0.6 \pm 0.4^{b}$ \\
\hline DLA & $4.3 \pm 1.6^{b}$ & $2.5 \pm 0.7^{\mathrm{a}}$ & $0.9 \pm 0.7^{\mathrm{a}}$ & $7.6 \pm 2.0^{b}$ & -3 \\
\hline DHA & $3.1 \pm 1.6^{b}$ & $2.0 \pm 1.1^{\mathrm{a}}$ & $0.8 \pm 1.1^{\mathrm{a}}$ & $6.0 \pm 2.6^{b}$ & $0.4 \pm 0.5^{b}$ \\
\hline
\end{tabular}

${ }^{1}$ All values are mean $\pm \mathrm{SD}(n=12) .{ }^{2}$ Values with the different superscript letters in a column are significantly different from one another as determined by one-way ANOVA followed by Duncan's multiple range test, $p<0.05$.

${ }^{3}$ No ACF observed. ${ }^{4}$ All rats were administered with DMH/DSS. C, AIN-93G diet; D, AIN-93G containing $10 \%$ djulis; DLA, AIN-93G containing 10\% djulis $+5 \times 10^{6} \mathrm{cfu}$ L. acidophilus/g; DHA, AIN-93G containing 10\% djulis + $5 \times 10^{7} \mathrm{cfu}$ L. acidophilus/g.

\subsection{Mucin Production by ACF and MDF}

The results of HIDAB-stained colons showed that groups D, DLA, and DHA had significantly lower numbers of SIM-ACF in the distal colon compared to group C (Table 8). MDF, an advanced precancerous lesion, was induced in all DMH/DSS-treated groups (Table 9). All djulis-treated groups showed a slightly lower MDF incidence than group $C$ while the numbers of MDF in groups D, DLA, and DHA were significantly lower compared to group C (Table 9).

Table 8. Effects of djulis and Lactobacillus acidophilus on DMH/DSS-induced ACF according to the type of mucin produced by foci in the distal colon of male F344 rats ${ }^{1,2}$.

\begin{tabular}{cccc}
\hline \multirow{2}{*}{ Group $^{3}$} & \multicolumn{3}{c}{ Number of ACF Producing $^{4}\left(\mathbf{n u m b e r} / \mathbf{c m}^{2}\right.$ ) } \\
\cline { 2 - 4 } & SUM $^{\mathbf{5}}$ & MIX & SIM \\
\hline C & $0.2 \pm 0.4^{\mathrm{a}}$ & $0.2 \pm 0.5^{\mathrm{a}}$ & $10.5 \pm 4.2^{\mathrm{a}}$ \\
D & $0.1 \pm 0.2^{\mathrm{a}}$ & $0.1 \pm 0.2^{\mathrm{a}}$ & $7.5 \pm 3.4^{\mathrm{b}}$ \\
DLA & $0.4 \pm 0.6^{\mathrm{a}}$ & $0.0 \pm 0.0^{\mathrm{a}}$ & $7.3 \pm 2.1^{\mathrm{b}}$ \\
DHA & $0.4 \pm 0.6^{\mathrm{a}}$ & $0.1 \pm 0.2^{\mathrm{a}}$ & $5.8 \pm 2.5^{\mathrm{b}}$ \\
\hline
\end{tabular}

${ }^{1}$ All values are mean $\pm \mathrm{SD}(n=12) .{ }^{2}$ Values with the different superscript letters in a column are significantly different from one another as determined by one-way ANOVA followed by Duncan's multiple range test, $p<0.05$. ${ }^{3}$ All rats were administered with DMH/DSS. C, AIN-93G diet; D, AIN-93G containing 10\% djulis; DLA, AIN-93G containing 10\% djulis $+5 \times 10^{6}$ L. acidophilus; DHA, AIN-93G containing 10\% djulis $+5 \times 10^{7}$ L. acidophilus. ${ }^{4}$ SUM, sulfomucin; MIX, mixed sulfumucin and sialomucin; SIM, sialomucin. ${ }^{5}$ Number of rats with SUM-ACF, MIX-ACF, or SIM-ACF. 
Table 9. Effects of djulis and Lactobacillus acidophilus on DMH/DSS-induced MDF in the colon of male F344 rats ${ }^{1,2}$.

\begin{tabular}{cccc}
\hline Group $^{3}$ & $\begin{array}{c}\text { MDF Incidence (Number of } \\
\text { Rats with MDF/Total Rats) }\end{array}$ & $\begin{array}{c}\text { Number of MDF } \\
\text { (Number/cm } \mathbf{~}^{\text {) }}\end{array}$ & $\begin{array}{c}\text { MDF Multiplicity } \\
\text { (Number of AC/MDF) }\end{array}$ \\
\hline C & $67 \%(8 / 12)$ & $0.42 \pm 0.38^{\mathrm{a}}$ & $1.4 \pm 0.5^{\mathrm{a}}$ \\
D & $42 \%(5 / 12)$ & $0.10 \pm 0.14^{\mathrm{b}}$ & $1.2 \pm 0.4^{\mathrm{a}}$ \\
DLA & $33 \%(4 / 12)$ & $0.09 \pm 0.14^{\mathrm{b}}$ & $1.0 \pm 0.0^{\mathrm{a}}$ \\
DHA & $8 \%(1 / 12)$ & $0.01 \pm 0.04^{\mathrm{b}}$ & $1.0 \pm 0.0^{\mathrm{a}}$ \\
\hline
\end{tabular}

${ }^{1}$ All values are mean $\pm \mathrm{SD}(n=12) .{ }^{2}$ Values with the different superscript letters in a column are significantly different from one another as determined by one-way ANOVA followed by Duncan's multiple range test, $p<0.05 .{ }^{3}$ All rats were administered with DMH/DSS. C, AIN-93G diet; D, AIN-93G containing 10\% djulis; DLA, AIN-93G containing $10 \%$ djulis $+5 \times 10^{6} \mathrm{cfu}$ L. acidophilus/g; DHA, AIN-93G containing $10 \%$ djulis $+5 \times 10^{7} \mathrm{cfu}$ L. acidophilus/g.

\subsection{Expression of Proliferation- and Inflammation-Related Proteins}

DMH/DSS administration (group C) significantly upregulated the expressions of PCNA (a proliferation-related protein) and COX-2 (an inflammation-related protein). Both groups DLA and DHA had significantly lower PCNA and COX-2 expressions than group C (Figure 5).

(a) PCNA

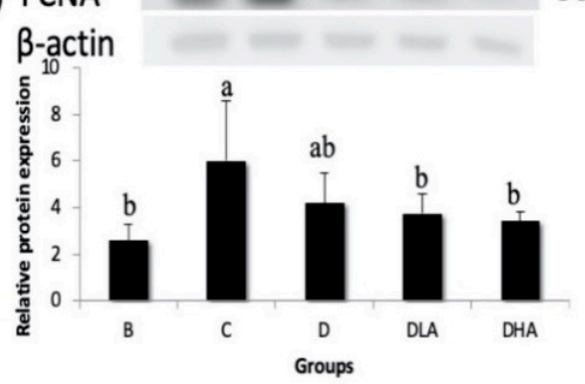

30kDa (b) COX-2

$$
\beta \text {-actin }
$$

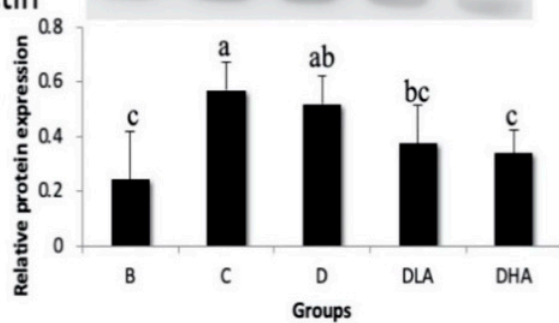

$75 \mathrm{kDa}$

Figure 5. Effects of djulis and Lactobacillus acidophilus on the expressions of proliferating cell nuclear antigen (PCNA) (a) and cyclooxygenase-2 (COX-2) (b) in the distal colon of male F344 rats. The bars represent mean \pm S.D. $(n=4-6)$. Different letters above the error bars indicate a significant difference as determined by one-way ANOVA followed by Ducan's multiple range test, $p<0.05$. All rats except those in group B were administered with DMH/DSS. C, AIN-93G diet; D, AIN-93G containing 10\% djulis; DLA, AIN-93G containing 10\% djulis $+5 \times 10^{6} \mathrm{cfu}$ L. acidophilus/g; DHA, AIN-93G containing $10 \%$ djulis $+5 \times 10^{7}$ cfu L. acidophilus/g.

\subsection{Expression of Apoptosis-Related Proteins}

DMH/DSS treatment (group C) significantly downregulated pro-apoptotic Bax expression, upregulated anti-apoptotic $\mathrm{Bcl}-2$ expression, and thus decreased the Bax/Bcl-2 ratio compared with group B (Figure 6). Group DHA recovered Bax expression to a level similar to group B while groups D, DLA, and DHA had significantly lower Bcl-2 expression compared with group C (Figure 6). The $\mathrm{Bax} / \mathrm{Bcl}-2$ ratio was elevated significantly in groups DLA and DHA compared with group C (Figure 6). $\mathrm{DMH} / \mathrm{DSS}$ treatment (group C) also significantly downregulated the expression of pro-apoptotic caspase-3, which recovered in group DHA compared with group C (Figure 6). 
(a) Bax

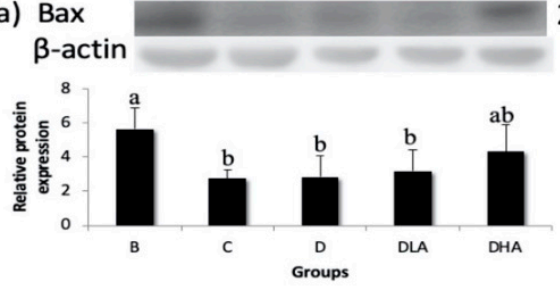

(c)

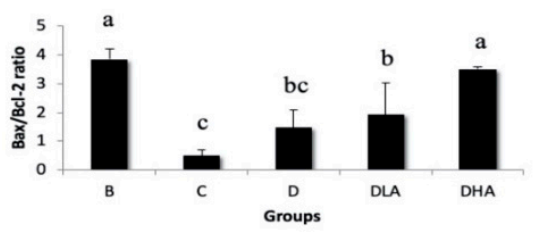

(b)

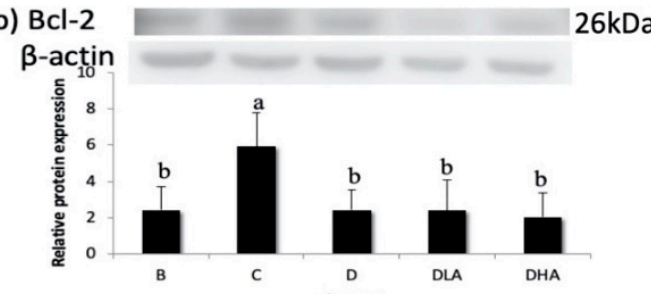

(d) Caspase-3

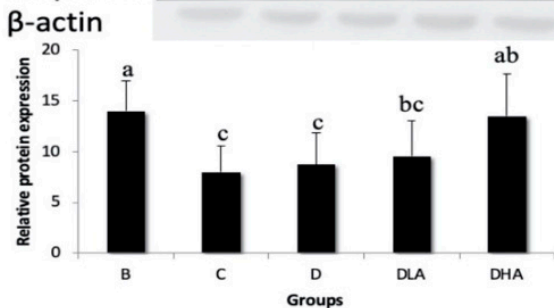

Figure 6. Effects of djulis and Lactobacillus acidophilus on the expressions of Bcl-2-associated X (Bax) (a), B-cell lymphoma 2 (Bcl-2) (b), Bax/Bcl-2 ratio (c), and caspase-3 (d) in the distal colon of male F344 rats. The bars represent mean \pm S.D. $(n=4-6)$. Different letters above the error bars indicate significant difference as determined by one-way ANOVA followed by Ducan's multiple range test, $p<0.05$. All rats except those in group B were administered with DMH/DSS. C, AIN-93G diet; D, AIN-93G containing 10\% djulis; DLA, AIN-93G containing $10 \%$ djulis $+5 \times 10^{6} \mathrm{cfu} \mathrm{L}$. acidophilus/g; DHA, AIN-93G containing $10 \%$ djulis $+5 \times 10^{7} \mathrm{cfu}$ L. acidophilus/g.

\section{Discussion}

Overall, the present study showed that dietary treatment with either djulis alone or in combination with L. acidophilus showed a preventive effect on DMH/DSS-induced colon carcinogenesis in rats. The preventive effects could be proven by the reduction of distal ACF, the low number of MDF, and the decreased expression of $\mathrm{Bcl}-2$ in all djulis-treated groups. Moreover, the synbiotic combination of djulis and L. acidophilus showed better inhibitory effects on the formation of large ACF and the expressions of PCNA and COX-2, as well as a better enhancing effect on the Bax/Bcl-2 ratio and caspase-3 expression compared to djulis alone.

The model of DMH/DSS-induced inflammation-associated colon carcinogenesis in rats has been widely used in many studies. Animals are often given DSS shortly after injection of DMH, which causes a decrease in the secretion of SUM-type mucin in the mucosa, impaired intestinal barrier function, induction of intestinal inflammation, and acceleration of CRC development [29]. In addition, as a promoter of CRC, DSS can significantly promote the formation of MDF [30]. Therefore, we used DMH and DSS to induce colitis-associated carcinogenesis in this study. The ACF incidence rates of all $\mathrm{DMH} / \mathrm{DSS}$-treated groups were $100 \%$, representing successfully induced colon carcinogenesis by the $\mathrm{DMH} / \mathrm{DSS}$ treatment.

ACF is a precancerous lesion of CRC in rodents and humans, which may progress to early and advanced adenomas [31,32]. As the total number of colonic ACF increased, the risk of CRC also increased [33]. In the present study, group DHA, which combined djulis with a high dose of L. acidophilus, significantly reduced the total ACF number compared to group C. Besides, the number of ACs in ACF can also be a marker to evaluate the progression of CRC. A previous study indicated that the greater the number of large ACF, the greater the risk of tumorigenesis [34]. In the present study, group $C$ had the highest number of large ACF among groups, whereas the combined treatment of djulis and L. acidophilus in groups DLA and DHA significantly reduced the numbers of large ACF. These results suggest the potential of djulis and L. acidophilus in chemoprevention of CRC.

Several studies indicated that chemical carcinogens induced colon cancer progression primarily by causing damage to the colonic mucosa [35]. ACF mainly appear in the distal colon at an early stage and expand to the proximal colon during advanced progression, and thus there is a relatively 
high number of ACF in the middle and distal colons [36,37]. A similar result was found in this study. ACF mainly distributed in the distal colon of all DMH/DSS-treated groups. Furthermore, both djulis alone and the combination of djulis with L. acidophilus significantly decreased the ACF number in the distal colon. These findings demonstrate that djulis and L. acidophilus have the ability to prevent colon carcinogenesis through inhibiting ACF development at an early stage.

Secretion of colonic mucins may change during the progression of CRC. A previous study indicated that secretion of mucin in ACF would gradually change from SUM to SIM [38]. It was also mentioned in another study that SIM-ACF had a higher hyperplastic index in the crypt, more dysplasia, and larger abnormal crypts compared to SUM-ACF [27]. In the present study, combined treatment of djulis and L. acidophilus (groups D, DLA, and DHA) significantly reduced the number of SIM-ACF compared to group C. It suggests that either djulis alone or the combination of djulis with L. acidophilus could inhibit the progress of CRC by regulating the colonic secretion of mucins.

A previous study found that both azoxymethane (AOM) and DMH promoted the formation of MDF in the colon [39]. In the present study, groups D, DLA, and DHA had a significantly lower MDF number than group C. Moreover, group DHA had the lowest MDF incidence. MDF that exhibit absent or scant production of mucin carry alterations in cell signaling pathways and gene mutations, with a frequency similar to that observed in tumors [40]. It has been proven that the number of MDF was positively correlated to the incidence of CRC [41]. These results show that either djulis alone or the combination of djulis with L. acidophilus have an inhibitory effect on the progression from primary to advanced precancerous lesions during colon carcinogenesis.

The present study showed that the fecal count of L. acidophilus in group DHA was significantly higher than that in group C. Previous studies have shown that the induction by DMH and DSS will lead to an increase in the intestinal $\mathrm{pH}$, and thus reduce the number of intestinal probiotics, such as Lactobacillus and Bifidobacterium [42]. A similar phenomenon was found in patients with irritable bowel syndrome. After treatment with L. acidophilus ( $10^{9} \mathrm{cfu} /$ day) and dietary fiber (consisting of $90 \%$ inulin and $10 \%$ oligofructose) for four weeks, the content of L. acidophilus in the feces was significantly increased compared to the placebo group, which confirmed that synbiotics can modulate the intestinal microflora [43]. A preliminary study in our laboratory demonstrated that the combination of probiotic L. acidophilus and germinated brown rice rich in dietary fiber suppressed DMH/DSS-induced colonic precancerous lesions via regulation of antioxidation and apoptosis in rats [44]. These findings suggest that such a synbiotic combination may be a potential functional food or chemopreventive agent for the control of CRC [44]. Meanwhile, the present study proved that the combination of djulis and a high dose of L. acidophilus improved DMH/DSS-induced reduction of L. acidophilus in feces. Overall, it is speculated that djulis could provide prebiotic dietary fiber for promoting the growth of L. acidophilus in the intestine.

The cecum is the main fermentation organ in rodents. Short-chain fatty acids (SCFAs) produced by fermentation can maintain intestinal epithelial cells, reduce intestinal $\mathrm{pH}$, and stimulate the growth of probiotics [45]. Studies showed that simultaneous administration of inulin and probiotics to mice increased the cecal weight, which represented a higher microbial content [46]. Femia et al. [47] pointed out that in an AOM-induced CRC rat model, the combination of inulin and probiotics (Lactobacillus rhamnosus and Bifidobacterium lactis) increased the concentration of SCFAs in the gut and inhibited the formation of ACF. Moreover, the synbiotic combination showed a stronger inhibitory effect on ACF than the probiotics or prebiotics alone [47]. In the present study, the relative cecum content weight was negatively correlated to the total ACF number in the distal colon $(r=-0.51$, $p<0.05)$ and positively correlated to caspase-3 protein expression $(r=0.79, p<0.0001)$. It suggests that synbiotics may inhibit the formation of colonic precancerous lesions by promoting fermentation in the cecum.

Chronic inflammation plays an important role in cancer development in several tissues, including the large intestine. The progression of CRC is accelerated by COX-2, which may promote cell proliferation, anti-apoptosis, invasion, metastasis, angiogenesis, and drug resistance in colon cancer [48]. 
In the present study, the expression of inflammation-related COX-2 was increased by DMH/DSS treatment; conversely, COX-2 expression was reduced by either djulis alone or the combination of djulis with L. acidophilus. Moreover, the combination of djulis with a high dose of L. acidophilus showed the best inhibitory effect on COX-2 expression. These findings suggest that djulis and L. acidophilus may suppress colon carcinogenesis via an inflammation-associated pathway.

Although djulis alone had no effect on proliferation-related PCNA, the combination of djulis with L. acidophilus reduced PCNA expression in the present study. Besides, the number of SIM-ACF was positively correlated to PCNA expression $(r=0.55, p<0.05)$. A previous study found that both inhibition of PCNA expression and promotion of caspase- 3 expression were confirmed in the activation of the extrinsic pathway of apoptosis [49]. Increasing the Bax/Bcl-2 ratio or inhibiting Bcl-2 expression, both markers of apoptosis, by treatment with bioactive compounds in colon cancer cells limited their growth [50,51]. The present study found that the combination of djulis with L. acidophilus could increase the $\mathrm{Bax} / \mathrm{Bcl}-2$ ratio and caspase-3 expression while treatment with djulis alone had no such effect. It suggests that the combination of djulis with L. acidophilus may inhibit cell proliferation and promote apoptosis in the DMH/DSS-induced CRC animal model.

In this study, $10 \%$ djulis in the experimental diet is equal to $44 \mathrm{~g}$ djulis for a $60 \mathrm{~kg}$ human per day. Besides, the doses of probiotics used in the DLA and DHA groups are equal to $2.5 \times 10^{9}$ and $2.5 \times 10^{10} \mathrm{cfu}$ L. acidophilus for a $60 \mathrm{~kg}$ human per day, respectively. It is easy to have these doses of probiotics from commercial yogurts, which usually contain $10^{8}$ to $10^{10} \mathrm{cfu}$ probiotics in each bottle. Therefore, the doses of djulis and L. acidophilus used in this study are feasible for humans to take in daily life.

\section{Conclusions}

Djulis, a cereal grain rich in prebiotic dietary fiber and chemopreventive substances, was proven to have an anti-cancer potential in inflammation-associated colon carcinogenesis in the present study. The combination of djulis and L. acidophilus as synbiotics may reduce the formation of colonic precancerous lesions by regulating colon cancer biomarkers, especially by inhibiting cell proliferation and inflammation, as well as promoting apoptosis. The synbiotic combination shows the best potential for chemoprevention of colon cancer.

Supplementary Materials: The following are available online at http://www.mdpi.com/2072-6643/12/1/103/s1, Figure S1: Cecal $\mathrm{pH}$ value of F344 rats.

Author Contributions: Conceptualization, C.-W.L., Y.-H.C., J.-H.C. and C.-K.S.; Methodology, H.-J.C., S.-M.H. and C.-K.S.; Formal analysis, C.-W.L. and Y.-H.C.; Writing-original draft preparation, C.-W.L., Y.-H.C. and C.-K.S.; Writing - review and editing, C.-W.L. and C.-K.S. All authors have read and agreed to the published version of the manuscript.

Funding: This research was funded by the grants from Ministry of Science and Technology, Taiwan (MOST103-2313-B-038-004 \& MOST104-2320-B-038-024).

Acknowledgments: This study was supported by the grants from Ministry of Science and Technology, Taiwan (MOST103-2313-B-038-004 \& MOST104-2320-B-038-024).

Conflicts of Interest: The authors declare no conflict of interest.

\section{References}

1. Bray, F.; Ferlay, J.; Soerjomataram, I.; Siegel, R.L.; Torre, L.A.; Jemal, A. Global cancer statistics 2018: GLOBOCAN estimates of incidence and mortality worldwide for 36 cancers in 185 countries. CA Cancer J. Clin. 2018, 68, 394-424. [CrossRef] [PubMed]

2. Ahmed, H.H.; Aglan, H.A.; Zaazaa, A.M.; Shalby, A.B.; El Toumy, S.A. Quercetin confers tumoricidal activity through multipathway mechanisms in a N-methylnitrosourea rat model of colon cancer. Asian Pac. J. Cancer Prev. 2016, 17, 4991-4998. [PubMed] 
3. Dermadi, D.; Valo, S.; Ollila, S.; Soliymani, R.; Sipari, N.; Pussila, M.; Sarantaus, L.; Linden, J.; Baumann, M.; Nyström, M. Western diet deregulates bile acid homeostasis, cell proliferation, and tumorigenesis in colon. Cancer Res. 2017, 77, 3352-3363. [CrossRef] [PubMed]

4. Gunasekaran, S.; Venkatachalam, K.; Namasivayam, N. Anti-inflammatory and anticancer effects of p-methoxycinnamic acid, an active phenylpropanoid, against 1, 2-dimethylhydrazine-induced rat colon carcinogenesis. Mol. Cell. Biochem. 2019, 451, 117-129. [CrossRef] [PubMed]

5. Roseweir, A.K.; Powell, A.G.; Bennett, L.; Van Wyk, H.C.; Park, J.; McMillan, D.C.; Horgan, P.G.; Edwards, J. Relationship between tumour PTEN/Akt/COX-2 expression, inflammatory response and survival in patients with colorectal cancer. Oncotargets 2016, 7, 70601. [CrossRef] [PubMed]

6. Zha, S.; Yegnasubramanian, V.; Nelson, W.G.; Isaacs, W.B.; De Marzo, A.M. Cyclooxygenases in cancer: Progress and perspective. Cancer Lett. 2004, 215, 1-20. [CrossRef]

7. Du, W.; Hong, J.; Wang, Y.C.; Zhang, Y.J.; Wang, P.; Su, W.Y.; Lin, Y.W.; Lu, R.; Zou, W.P.; Xiong, H. Inhibition of JAK2/STAT3 signalling induces colorectal cancer cell apoptosis via mitochondrial pathway. J. Cell. Mol. Med. 2012, 16, 1878-1888. [CrossRef]

8. Yim, N.H.; Gu, M.J.; Hwang, Y.H.; Cho, W.K.; Ma, J.Y. Water extract of Galla Rhois with steaming process enhances apoptotic cell death in human colon cancer cells. Integr. Med. Res. 2016, 5, 284-292. [CrossRef]

9. Bird, R.P. Observation and quantification of aberrant crypts in the murine colon treated with a colon carcinogen: Preliminary findings. Cancer Lett. 1987, 37, 147-151. [CrossRef]

10. Filipe, M.I. Mucous secretion in rat colonic mucosa during carcinogenesis induced by dimethylhydrazine. A morphological and histochemical study. Br. J. Cancer 1975, 32, 60-77. [CrossRef]

11. Femia, A.P.; Dolara, P.; Caderni, G. Mucin-depleted foci (MDF) in the colon of rats treated with azoxymethane (AOM) are useful biomarkers for colon carcinogenesis. Carcinogenesis 2004, 25, 277-281. [CrossRef] [PubMed]

12. Suzui, M.; Morioka, T.; Yoshimi, N. Colon preneoplastic lesions in animal models. J. Toxicol. Pathol. 2013, 26, 335-341. [CrossRef] [PubMed]

13. Chyau, C.C.; Chu, C.C.; Chen, S.Y.; Duh, P.D. The Inhibitory Effects of Djulis (Chenopodium formosanum) and Its Bioactive Compounds on Adipogenesis in 3T3-L1 Adipocytes. Molecules 2018, 23, 1780. [CrossRef] [PubMed]

14. Chu, C.-C.; Chen, S.-Y.; Chyau, C.-C.; Fu, Z.-H.; Liu, C.-C.; Duh, P.-D. Protective effect of Djulis (Chenopodium formosanum) and its bioactive compounds against carbon tetrachloride-induced liver injury, in vivo. J. Funct. Foods 2016, 26, 585-597. [CrossRef]

15. Lin, T.A.; Ke, B.J.; Cheng, C.S.; Wang, J.J.; Wei, B.L.; Lee, C.L. Red quinoa bran extracts protects against carbon tetrachloride-induced liver injury and fibrosis in mice via activation of antioxidative enzyme systems and blocking TGF-beta1 pathway. Nutrients 2019, 11, 395. [CrossRef] [PubMed]

16. Tsai, P.J.; Chen, Y.S.; Sheu, C.H.; Chen, C.Y. Effect of nanogrinding on the pigment and bioactivity of Djulis (Chenopodium formosanum Koidz.). J. Agric. Food Chem. 2011, 59, 1814-1820. [CrossRef]

17. Hong, Y.H.; Huang, Y.L.; Liu, Y.C.; Tsai, P.J. Djulis (Chenopodium formosanum Koidz.) Water Extract and Its Bioactive Components Ameliorate Dermal Damage in UVB-Irradiated Skin Models. Biomed. Res. Int. 2016, 2016. [CrossRef]

18. Broekaert, W.F.; Courtin, C.M.; Verbeke, K.; Van de Wiele, T.; Verstraete, W.; Delcour, J.A. Prebiotic and other health-related effects of cereal-derived arabinoxylans, arabinoxylan-oligosaccharides, and xylooligosaccharides. Crit. Rev. Food Sci. Nutr. 2011, 51, 178-194. [CrossRef]

19. Ambalam, P.; Raman, M.; Purama, R.K.; Doble, M. Probiotics, prebiotics and colorectal cancer prevention. Best Pract. Res. Clin. Gastroenterol. 2016, 30, 119-131. [CrossRef]

20. Chong, E.S.L. A potential role of probiotics in colorectal cancer prevention: Review of possible mechanisms of action. World J. Microbiol. Biotechnol. 2014, 30, 351-374. [CrossRef]

21. Lee, C.W.; Chen, H.J.; Xie, G.R.; Shih, C.K. Djulis (Chenopodium formosanum) prevents colon carcinogenesis via regulating antioxidative and apoptotic pathways in rats. Nutrients 2019, 11, 2168. [CrossRef] [PubMed]

22. Li, S.C.; Hsu, W.F.; Chang, J.S.; Shih, C.K. Combination of Lactobacillus acidophilus and Bifidobacterium animalis subsp. lactis shows a stronger anti-inflammatory effect than individual strains in HT-29 Cells. Nutrients 2019, 11, 969. [CrossRef] [PubMed]

23. Conrad, P.B.; Miller, D.P.; Cielenski, P.R.; de Pablo, J.J. Stabilization and preservation of Lactobacillus acidophilus in saccharide matrices. Cryobiology 2000, 41, 17-24. [CrossRef] [PubMed] 
24. du Toit, M.; Franz, C.M.; Dicks, L.M.; Schillinger, U.; Haberer, P.; Warlies, B.; Ahrens, F.; Holzapfel, W.H. Characterisation and selection of probiotic lactobacilli for a preliminary minipig feeding trial and their effect on serum cholesterol levels, faeces $\mathrm{pH}$ and faeces moisture content. Int. J. Food Microbiol. 1998, 40, 93-104. [CrossRef]

25. Challa, A.; Rao, D.R.; Chawan, C.B.; Shackelford, L. Bifidobacterium longum and lactulose suppress azoxymethane-induced colonic aberrant crypt foci in rats. Carcinogenesis 1997, 18, 517-521. [CrossRef]

26. Li, S.C.; Chen, C.M.; Lin, S.H.; Chiang, W.; Shih, C.K. Effects of adlay bran and its ethanolic extract and residue on preneoplastic lesions of the colon in rats. J. Sci. Food Agric. 2011, 91, 547-552. [CrossRef]

27. Jenab, M.; Chen, J.-m.; Thompson, L.U. Sialomucin production in aberrant crypt foci relates to degree of dysplasia and rate of cell proliferation. Cancer Lett. 2001, 165, 19-25. [CrossRef]

28. Lau, D.S.; Archer, M.C. Fatty acid synthase is over-expressed in large aberrant crypt foci in rats treated with azoxymethane. Int. J. Cancer 2009, 124, 2750-2753. [CrossRef]

29. Dawson, P.A.; Huxley, S.; Gardiner, B.; Tran, T.; McAuley, J.L.; Grimmond, S.; McGuckin, M.A.; Markovich, D. Reduced mucin sulfonation and impaired intestinal barrier function in the hyposulfataemic NaS1 null mouse. Gut 2009, 58, 910-919. [CrossRef]

30. Femia, A.P.; Dolara, P.; Luceri, C.; Salvadori, M.; Caderni, G. Mucin-depleted foci show strong activation of inflammatory markers in 1,2-dimethylhydrazine-induced carcinogenesis and are promoted by the inflammatory agent sodium dextran sulfate. Int. J. Cancer 2009, 125, 541-547. [CrossRef]

31. Rosenberg, D.W.; Giardina, C.; Tanaka, T. Mouse models for the study of colon carcinogenesis. Carcinogenesis 2009, 30, 183-196. [CrossRef] [PubMed]

32. Wargovich, M.J.; Brown, V.R.; Morris, J. Aberrant crypt foci: The case for inclusion as a biomarker for colon cancer. Cancers 2010, 2, 1705-1716. [CrossRef] [PubMed]

33. Ezuka, A.; Sakai, E.; Kawana, K.; Nagase, H.; Kakuta, Y.; Uchiyama, S.; Ohkubo, H.; Higurashi, T.; Nonaka, T.; Endo, H.; et al. Association between factors associated with colorectal cancer and rectal aberrant crypt foci in humans. Oncol. Lett. 2015, 10, 3689-3695. [CrossRef]

34. Kasdagly, M.; Radhakrishnan, S.; Reddivari, L.; Veeramachaneni, D.R.; Vanamala, J. Colon carcinogenesis: Influence of Western diet-induced obesity and targeting stem cells using dietary bioactive compounds. Nutrition 2014, 30, 1242-1256. [CrossRef] [PubMed]

35. Doi, K.; Fujioka, M.; Sokuza, Y.; Ohnishi, M.; Gi, M.; Takeshita, M.; Kumada, K.; Kakehashi, A.; Wanibuchi, H. Chemopreventive action by ethanol-extracted Brazilian green propolis on post-initiation phase of inflammation-associated rat colon tumorigenesis. In Vivo 2017, 31, 187-197. [CrossRef] [PubMed]

36. Kinjo, T.; Suzui, M.; Morioka, T.; Nabandith, V.; Inamine, M.; Kaneshiro, T.; Arakaki, J.; Nishimaki, T.; Yoshimi, N. Distribution of preneoplastic lesions and tumors, and beta-catenin gene mutations in colon carcinomas induced by 1,2-dimethylhydrazine plus dextran sulfate sodium. J. Exp. Clin. Cancer Res. 2006, 25, 89-95. [PubMed]

37. Gomides, A.F.; de Paula, S.O.; Goncalves, R.V.; de Oliveira, L.L.; Ferreira, C.L.; Comastri, D.S.; Peluzio Mdo, C. Prebiotics prevent the appearance of aberrant crypt foci (ACF) in the colon of BALB/c mice for increasing the gene expression of p16 protein. Nutr. Hosp. 2014, 30, 883-890.

38. Milosevic, V.; Vukmirovic, F.; Zindovic, M.; Krstic, M.; Milenkovic, S.; Jancic, S. Interplay between expression of leptin receptors and mucin histochemical aberrations in colorectal adenocarcinoma. Rom. J. Morphol. Embryol. 2015, 56, 709-716.

39. Caderni, G.; Femia, A.P.; Giannini, A.; Favuzza, A.; Luceri, C.; Salvadori, M.; Dolara, P. Identification of mucin-depleted foci in the unsectioned colon of azoxymethane-treated rats: Correlation with carcinogenesis. Cancer Res. 2003, 63, 2388-2392.

40. Femia, A.P.; Bendinelli, B.; Giannini, A.; Salvadori, M.; Pinzani, P.; Dolara, P.; Caderni, G. Mucin-depleted foci have $\beta$-catenin gene mutations, altered expression of its protein, and are dose-and time-dependent in the colon of 1, 2-dimethylhydrazine-treated rats. Int. J. Cancer 2005, 116, 9-15. [CrossRef]

41. Cui, C.; Takamatsu, R.; Doguchi, H.; Matsuzaki, A.; Saio, M.; Yoshimi, N. Pre-neoplastic lesion, mucin-depleted foci, reveals de novo high-grade dysplasia in rat colon carcinogenesis. Oncol. Rep. 2012, 27, 1365-1370. [PubMed]

42. Zhang, Z.; Shen, P.; Liu, J.; Gu, C.; Lu, X.; Li, Y.; Cao, Y.; Liu, B.; Fu, Y.; Zhang, N. In Vivo study of the efficacy of the essential oil of Zanthoxylum bungeanum pericarp in dextran sulfate sodium-induced murine experimental colitis. J. Agric. Food Chem. 2017, 65, 3311-3319. [CrossRef] [PubMed] 
43. Bogovic Matijasic, B.; Obermajer, T.; Lipoglavsek, L.; Sernel, T.; Locatelli, I.; Kos, M.; Smid, A.; Rogelj, I. Effects of synbiotic fermented milk containing Lactobacillus acidophilus La-5 and Bifidobacterium animalis ssp. lactis BB-12 on the fecal microbiota of adults with irritable bowel syndrome: A randomized double-blind, placebo-controlled trial. J. Dairy Sci. 2016, 99, 5008-5021. [CrossRef]

44. Lin, P.Y.; Li, S.C.; Lin, H.P.; Shih, C.K. Germinated brown rice combined with Lactobacillus acidophilus and Bifidobacterium animalis subsp. lactis inhibits colorectal carcinogenesis in rats. Food Sci. Nutr. 2019, 7, 216-224. [CrossRef] [PubMed]

45. Knapp, B.K.; Bauer, L.L.; Swanson, K.S.; Tappenden, K.A.; Fahey, G.C., Jr.; de Godoy, M.R. Soluble fiber dextrin and soluble corn fiber supplementation modify indices of health in cecum and colon of Sprague-Dawley rats. Nutrients 2013, 5, 396-410. [CrossRef] [PubMed]

46. Kuo, S.M.; Merhige, P.M.; Hagey, L.R. The effect of dietary prebiotics and probiotics on body weight, large intestine indices, and fecal bile acid profile in wild type and IL10-/- mice. PLoS ONE 2013, 8, e60270. [CrossRef]

47. Femia, A.P.; Luceri, C.; Dolara, P.; Giannini, A.; Biggeri, A.; Salvadori, M.; Clune, Y.; Collins, K.J.; Paglierani, M.; Caderni, G. Antitumorigenic activity of the prebiotic inulin enriched with oligofructose in combination with the probiotics Lactobacillus rhamnosus and Bifidobacterium lactis on azoxymethane-induced colon carcinogenesis in rats. Carcinogenesis 2002, 23, 1953-1960. [CrossRef]

48. Karpisheh, V.; Nikkhoo, A.; Hojjat-Farsangi, M.; Namdar, A.; Azizi, G.; Ghalamfarsa, G.; Sabz, G.; Yousefi, M.; Yousefi, B.; Jadidi-Niaragh, F. Prostaglandin E2 as a potent therapeutic target for treatment of colon cancer. Prostaglandins Other Lipid Mediat. 2019. [CrossRef]

49. Sasso, C.V.; Santiano, F.E.; Campo Verde Arbocco, F.; Zyla, L.E.; Semino, S.N.; Guerrero-Gimenez, M.E.; Pistone Creydt, V.; Lopez Fontana, C.M.; Caron, R.W. Estradiol and progesterone regulate proliferation and apoptosis in colon cancer. Endocr. Connect. 2019, 8, 217-229. [CrossRef]

50. Kim, D.H.; Kim, M.J.; Sung, B.; Suh, H.; Jung, J.H.; Chung, H.Y.; Kim, N.D. Resveratrol analogue, HS-1793, induces apoptotic cell death and cell cycle arrest through downregulation of AKT in human colon cancer cells. Oncol. Rep. 2017, 37, 281-288. [CrossRef]

51. Encarnacao, J.C.; Pires, A.S.; Amaral, R.A.; Goncalves, T.J.; Laranjo, M.; Casalta-Lopes, J.E.; Goncalves, A.C.; Sarmento-Ribeiro, A.B.; Abrantes, A.M.; Botelho, M.F. Butyrate, a dietary fiber derivative that improves irinotecan effect in colon cancer cells. J. Nutr. Biochem. 2018, 56, 183-192. [CrossRef] [PubMed] 